is it a matter for the General Medical Council, the BMA, or the provident associations.

\section{Patrick Hall-Smith}

Hove,

Sussex BN3 3JD

SIR,- The general practice trainers in Edgware (27 February, p 640) are to be congratulated on taking a stand against the increasing practice of self referral to consultants and are possibly underplaying their anxieties lest they be accused of self interest.

Every consultant has occasional patients who arrive without any introduction from their general practitioner, and this is not known until the patient is in the consulting room. Sometimes this occurs because a lesion has been picked up at an insurance medical examination or routine occupational health examination, and referral comes that way. It seems only reasonable then to try to help the patient on the strict understanding that the genera practitioner is informed by an explanatory letter.

Self referral, however, should be discouraged because it is dangerous. In central London it is common for patients to refer themselves to and receive treatment from physicians and surgeons who are not qualified to deal with their illness.

The other danger of self referral is that a consultant may not receive necessary information. The good general practitioner tells you a lot about the patient and his or her history, medications, and investigations, and also stops one consultant passing the patient on to another consultant ad infinitum. The General Medical Council should look on this matter as one of ethics.

GRANT WILLIAMS

Harley Street,

London WIN IAH

SIR,-Dr Gerald Michael and his colleagues wish to call down the collective powers (? wrath) of various august and provident bodies to avoid an apocalypse in general practice. The aim is to curtail the unprincipled activities of some patients and some consultants. As it was I who spoke up for the preservation of personal freedom (though totally within the context of the General Medical Council statements $)^{1}$ I would argue that the ideas of these authors are misdirected.

Assuming that the general practitioner rightfully holds such paternalistic control over the patient's access to specialist opinion, what guarantee can be given to patients that they can expect and find a really suitable patron? Let us focus on paediatrics - the specialty spotlighted by the authors. Where can the patient be assured that paediatric training is a compulsory part of vocational training now, to say nothing of what came before? Where is developmental screening and immunisation part of every general practitioner's service? Where is the universally applied appointments system that allows for the unpredictable and worrying illnesses of childhood? Where can parents rely on seeing a competent paediatric practitioner covering evenings, nights, and weekends?

Being a parent is a heavy and difficult responsibility, to say nothing of important social trends such as both parents working. Not surprisingly, people are prepared to buy their way out of more difficult choices. Doctors themselves register highly as users of a freer choice of medical (and educational) care for their dependants. And is it that expensive? (A consultant's fee does not cost much more to a health system than an inappropriate course of expensive antibiotics.)

Where good service and competence exist in general practice there is no evidence of decline and virtually no self referral by patients. Where these do not exist patients (especially parents) should pressurise any of the influential agencies to effect an improvement-but many will probably "invest in providents."

M M LIEBERMAN

Northwick Park Hospital,

Harrow, Middlesex HAl 3 U J

I General Medical Council. Professional conduct and discipline: fitness to practise. London: GMC, 1983:21.

SIR,-One of the best features of British medicine must be the existence of a stable network of genera practitioners acting both as gatekeepers to the specialist secondary services and as the most experienced general diagnosticians at the level of primary care. The issue raised by Dr Gerald Michael and others is therefore important, bu other changes also threaten to erode the role of the general practitioner.

For example, some districts are now segregatin the mentally ill and emotionally disturbed at a local rather than a regional level by developing com munity mental health centres, which accept "walk in" patients and referrals from all sources. This development may exclude the desirable diagnostic role of the patient's general practitioner and the contribution of his or her direct knowledge of that patient.

In general the use of non-medical practitioners (whether health visitors, community psychiatric nurses, nurse practitioners, or others) in an initia screening role, and the extent to which they accep direct referrals or refer to other non-medical professionals, is likely to occur in a haphazard way It remains to be seen whether these changes will be beneficial-detecting morbidity and pro viding more treatment-or merely fuel a form of therapeutic anarchy. The general practitioner is best equipped to moderate under these circumstances, but he may be swept aside.

Any decision to supplant the primary screening role of the general practitioner by those with less training (even if more specialised in some respect) is theoretically reducing the diagnostic quality of the service, although there may be gains in other directions. Such a move would be in contrast to the recommendations for secondary care, where an increase in quality of service depends on more assessment and treatment by consultants.

D M BOWKER

Birch Hill Hospital

Rochdale OL12 90B

SIR,-I agree with the Edgware trainers that the practice of seeing patients without a referral does seem to be increasing. I do not pretend to have any answers to this problem but I do have some questions.

Firstly, the only essential question is where doe the best interest of the patient lie? General practitioners do not have any inalienable rights in this area. Our responsibility for continuing care is our only real argument against this behaviour.

Secondly, when patients join our list how much trouble do we take to explain and negotiate the ethos of our practice? Patients have a right to contract which should include the right to continuing care and the need to seek a second opinion through their general practitioner

Thirdly, if patients should break this contract and, for whatever reason, a colleague decides he should see them what possible right does he have to make recommendations? The moral responsibility must lie with the consultant who sees the patient to see that anything that is thought by him to be important is carried out. He has in fact assumed the responsibility for continuing care. The essence of a referral is that an opinion is sought from a colleague whose opinion and judgment are valued. The referral carries the implication that any recommendations will be implemented. In the absence of this there is no referral and no such implication. In this context it should be remembered that under the terms and conditions of service of NHS general practitioners a prescription form FP10 is not allowable after a private consultation. The patient must pay for a prescription issued by the doctor who has been consulted as long as responsibility for the patient continues.

It is in the best interest of the patient to be guided through a possible maze of medical opinions by a good general practitioner. I doubt whether the behaviour that the Edgware trainers describe will ever appeal to a substantial number of our consultant colleagues as most of them see these arguments very clearly. Certainly I do not see it marking the end of general practice as we know it. The survival of general practice depends only on patients preferring to see general practitioners most of the time because they know them, feel more comfortable with them, and trust their judgment. Perhaps we should be concentrating on this.

DAVID BROOKS

Peterloo Medical Centre,

Manchester M24 4DZ

\section{Hypomagnesaemia and muscle function}

SIR,-Dr I Dørup and others (13 February, p 455) do not present data on muscle power assessed objectively in the subjects studied. We have described a young woman with anorexia nervosa who abused diuretics and developed modest hypomagnesaemia which caused profound muscle weakness and cardiac failure. 'She responded to an intravenous infusion of magnesium but died two years later of cardiorespiratory failure, which was again associated with hypomagnesaemia.

The muscle weakness in our patient was probably associated with severe depletion of magnesium and potassium in skeletal muscle. Although a study on cardiac muscle would be difficult, it is conceivable that similar changes occur there. Furthermore, the down regulation of sodium potassium pumps described by Dr Dørup and others would contribute to the development of cardiac failure as the importance of these pumps in the physiology of cardiac muscle contraction is well established. It is important to recognise that mild degrees of hypomagnesaemia may be associated with significant depletion of this ion in muscle. Prompt correction of any abnormality may reduce morbidity and mortality.

C W H HAVARD

\section{London W1N $1 \mathrm{DH}$}

1 Fonseca V, Havard CWH. Electrolyte disturbances and cardiac failure with hypomagnesaemia in anorexia nervosa. $\mathrm{Br} \mathrm{Med} \mathcal{J}$ 1985;291:1680-2.

\section{Prevalence of microalbuminuria in patients with insulin dependent diabetes}

SIR,-We found a similar percentage of positive tests for microalbuminuria to those found by Dr H H Parving and others (16 January, p 156) in both insulin dependent and non-insulin dependent diabetes using the more easily obtained single early morning urine specimen.

We screened 596 insulin dependent diabetics 